In: Wenban-Smith, F., Hosfield, R., Pope, M. \& Coward, F. (eds.) (2015) Settlement, Society and Cognition in Human Evolution, pp. 000-000. Cambridge University Press.

\title{
Local objects, distant symbols: Fission-fusion social systems and the evolution of human cognition
}

Matt Grove and Robin Dunbar

\begin{abstract}
Since the very beginnings of comparative ethnography researchers have noted the presence of discrete groupings within human social systems. In recent decades, study of the parallels between these groupings and those of fission-fusion primate societies has resulted in a body of theory that is potentially applicable to the archaeological and palaeoanthropological records of hominin evolution. Despite this, archaeologists have often been reluctant to attempt reconstructions of Palaeolithic society or incapable of synthesizing the necessary research from apparently incompatible disciplines. The work of Clive Gamble provides a notable exception to this rule, clearly articulating and applying a theory of hominin social change predicated upon the evidence of a series of expansions in the geographical scale of Palaeolithic social interaction. This paper employs Gamble's approach to make a closer examination of the socioecological context of fission-fusion in primate societies, with a particular focus on the cognitive demands of this sophisticated adaptation. A number of the specific cognitive abilities suggested to accompany expanded fission-fusion grouping behaviour depend upon an understanding of both past and future time that is absent or little developed in other primates. Archaeological evidence for the evolution of these abilities is assessed, demonstrating a close alignment with - and providing a deeper understanding of the appearance of local hominin networks and the eventual emergence of the social landscape.
\end{abstract}

\section{Introduction}

Relative to other primates, modern humans live social lives of remarkable complexity, maintaining relationships with other individuals over entire life-spans and across continental divides. The spatio-temporal scales over which we interact define our societyand highlight a marked break from other species. Nevertheless, there is clear evidence among some apes and monkeys of social systems that could be considered antecedent, or informative parallels, to our own. One such social system is characterised by the repeated division and aggregation of smaller groups into larger groups (termed 'fission-fusion': Kummer 1971). This apparently simple system is highly beneficial ecologically, yet leads to profound social and cognitive pressures. This paper will argue that these cognitive demands have played a considerable role in shaping the evolution of specific aspects of modern human cognition.

Gamble's (1993, 1996, 1998, 1999) network approach to Palaeolithic society, particularly as part of the British Academy's Archaeology of the Social Brain project, has facilitated the comparison of the social systems of extant primates, modern hunter-gatherers, and archaeologically documented populations within a single framework in which. group size during prehistory is linked to social complexity; social complexity as a whole is constrained by cognitive capacity, measured primarily by the relative size of the neocortex, and fissionfusion is an important signifier of social complexity, linking not only to a number of specific cognitive abilities but also to neocortical ratios in primates. We here combine Gamble's notion of the increasing scale of Palaeolithic life with a particular concern with the cognitive 
ramifications of stretching fission-fusion social organisation beyond the limits seen in extant primates. To this end, the following sections define and examine fission-fusion as a social system, survey work on the modern human fission-fusion system, introduce research on a number of cognitive abilities that may be tied specifically to this system, and discuss the evidence for those cognitive abilities (and for fission-fusion directly) in the archaeological record of the Palaeolithic.

\section{What is fission-fusion?}

The term fission-fusion (henceforth FF) refers to a form of social organisation in which an overall group or 'community' splits periodically into subgroups. FF can be seen as one end of a continuum of group cohesiveness, with the other represented by social groups whose members are in close spatial proximity continually. FF social organisation is found in a diverse range of animals including bats, equids, cetaceans, social carnivores and elephants. Among primates, the two species of chimpanzees, seven species of spider monkeys, and at least four baboon species (including the drill and mandrill) show clear and consistent evidence of FF social dynamics, as do some howler monkeys and some macaque species. FF appears to be driven by the need to dynamically adjust group sizes to a fluctuating resource base, allowing individuals to balance the costs and benefits of group living by adjusting the sizes of the subgroups in which they gather. Where limiting resources are clumped, or when predation risk is high, larger aggregations are predicted to occur; when predation risk is low and resources are evenly distributed, smaller groups will be more efficient. Furthermore, the timescales at which these variables change may vary; predation risk may always be higher at night, whereas resource distribution and density may change according to a seasonal cycle. Once established, however, FF has social ramifications that go far beyond its presumed ecological function.

As studies of primate FF have become more numerous, a series of finer grained distinctions have been made among social systems at the low cohesion end of the grouping spectrum. Rodseth and colleagues (1991) distinguish between 'atomistic' FF, where the smallest unit is the individual, and 'molecular' FF, where the smallest unit is a subgroup, normally comprising a male, females, and their offspring (the 'one-male unit'). Atomistic systems are the most fluid in that even subgroups will be of different composition from day to day, whereas the subgroups in a molecular system are relatively stable. Kappeler and van Schaik (2002) offer a similar dichotomy, but regard atomistic groups as practising true fission-fusion, while molecular groups are referred to instead as operating in 'multilevel' societies. Chimpanzees are the quintessential atomistic system; there are several levels of grouping, with a series of subgroups of approximately five individuals forming a neighbourhood of around 15 (Thompson et al. 2007), who in turn form a community of 45100 (see Lehmann et al. in press). Any given individual (with the exception of dependent young and occasional particular alliances) can encounter any other on any given day, with exchange of individuals between subgroups occurring routinely). Hamadryas baboons, on the other hand, are the classic example of a molecular or multilevel system, with four levels of grouping: several stable one-male units form a clan, several of which form a band. The key distinction is whether the lowest level groupings are stable or not. The apparent dichotomy between atomistic and multilevel societies breaks down, however, when we come to examine FF dynamics in modern humans.

\section{Fission-fusion in modern human societies}

Rodseth and colleagues (1991) suggest that humans adopt a composite form of primate society, "analogous to a chimpanzee community during the day and to a hamadryas band at night" (Rodseth et al. 1991, 239). The human combination of atomistic and molecular 
strategies makes us, in Kappeler and van Schaik's (2002) terms, both a fission-fusion and a multilevel society, and unique among primates and yet is universal among humans; . The multilevel aspect of human society has long been noted by hunter-gatherer ethnographers (e.g. Murdock 1949, 1969; Birdsell 1958, 1968), and and by psychologists for modern sedentary societies (see Hill and Dunbar 2003; Zhou et al. 2005; Roberts 2010). , suggesting that it is an ancient and important part of our evolutionary history.

While terms such as FF directly relate to the cohesiveness of the community, they do not comment directly on the actual spatial organisation of individuals at any particular level. Like hamadryas baboons, humans repeatedly aggregate at particular localities, with daily (or longer) forays radiating out from and returning to these localities (see e.g. Lee 1968, Yellen 1977, Binford 1980). This pattern identifies us as central place foragers, a foraging mode prompted in other animals primarily by either the presence of altricial young or the need to fission and travel widely in search of food. Though all humans engage in some form of FF behaviour, the spatio-temporal extent of the fission phase can vary considerably: Binford $(1978,1980)$ distinguishes between the relatively simple routines of 'foragers' and the more sophisticated radiating patterns of 'collectors' , Washburn (1982) contrasts immediate and delayed return foragers and Lieberman and Shea circulating and radiating mobility patterns (1994). Perreault and Brantingham (2011) have recently characterised the forager-collector continuum in terms of the distance travelled (or the time elapsed) between visits to the same central place location: with collectors return frequently to central places but reside there for longer durations, using wider foraging radii, while foragersreturn to central place locations only by chance at some later date amd fpr a re;atvoely short period of time, thus exploiting only a limited radius around it (Binford 1962; Grove 2009, 2010a).

Humans, then, are fission-fusion, multilevel, central place foragers. Though each of these aspects of social organisation can be found in numerous other animals, the combination of the three appears in no other living species. However, perhaps the most distinctive element of the human social adaptation is that our FF behaviour is expanded over far greater scales, both spatially and temporally, than that of any other animal; it is this 'release from proximity' (Rodseth et al. 1991, 240) that has become the focus of Gamble's $(1998,1999,2007)$ evolutionary scenario for the prehistoric development of human network structures. Mediated by the increasing use of artefacts as symbols and the linking of ever more distant locales within a social landscape created by the establishment of habitual paths and tracks, the gradual extension of social life is established throughout the Palaeolithic as local networks were incorporated into extended and ultimately global networks.

Larger group sizes, extended effective networks and, ultimately, extended 'social landscapes' require the storage of ever increasing quantities of information for longer and longer periods, and the transmission of that information over larger and larger distances. The handling of increasing quantities of information, whether iconic, indexical, or symbolic, can be expected to increase cognitive demands on individual hominins. The social brain hypothesis (Dunbar 1998, 2003) has demonstrated the constraint imposed by executive cognitive capacity on group size; this constraint has been used to infer a progression of group sizes that is broadly in agreement with the scheme advocated by Gamble's $(1998,1999)$ network approach. Furthermore, conclusions regarding the origins of language that form a central pillar of the SBH (Aiello and Dunbar 1993; Dunbar 1993, 2009) accord well with notions of an increasing requirement for information-handling over the course of human evolution. Building on the arguments of Gamble's network approach and employing the social brain framework in broad terms, the section below examines cognitive requirements that might be specific to FF rather than to increasing group size per se.

\section{Displacement}


The concept of displacement identified by Hockett $(1960,1963)$ as one of the 'design features of human language'describes the fact that "what is being communicated about can be removed, in time or space or both, from the setting in which the communication takes place" (Hockett 1960, 415) and is thus of particular relevance to the evolution of FF social systems and the 'release from proximity' in human societies. The uncoupling of relationships from spatial proximity is a direct social analogue of this process, and may therefore be equally demanding in cognitive terms; indeed, Rodseth and colleagues (1991, 240)go as far as to suggest that with this uncoupling "social evolution as a human affair was launched upon its career". Although there are possible examples of partial displacement in the vocalisations of baboons, gibbons, and vervets (Altmann 1967; Hockett and Altmann 1968; Cheney and Seyfarth 1990), it seems that humans alone are capable of routine displacement both linguistically and socially. However, there is some evidence from chimpanzees and baboons that may contradict this.

For example, Washoe was able to use sign language to ask one of her handlers to get her an orange from the car (Lieberman 1984). The negotiations between hamadryas baboon males about the direction in which to forage during the day and which waterhole they should meet at may be another example of displacement (Sigg and Stolba 1981). Chimpanzees, being an atomistic FF society, do of course handle social displacement in the wild, though this takes place over a limited spatio-temporal scale relative to that of modern humans. If we assume that the evolution of hominin FF has involved the stretching of a chimpanzee-like fission-fusion template, the interesting question is whether linguistic and social displacement directly co-evolved. To put this another way, how far could the spatio-temporal range of a chimpanzee community be stretched before an alternative form of information transmission became necessary? The SBH suggests that beyond a certain group size language becomes essential due to the need for an efficient mechanism of social bond maintenance; the above argument further suggests that the frequency of inter-individual contact in chimpanzee communities could not be reduced any further without relations between individuals breaking down.

\section{Object permanence}

A further ability required by animals living in FF societies is an understanding of object permanence: the ability to know that objects (or agents) continue to exist even though they are no longer apparent to the senses; (Piaget 1952). Though the precise timing of object permanence development in children has been questioned, the sequence of acquisition is well established and is mirrored in apes, monkeys, and some non-primate species (Gomez 2005). Potts (2004) has argued that the ability to track ephemeral and dispersed food sources among frugivorous primates would also have been beneficial in the social realm for FF species. Thus in solving the ecological problem of a variable and dispersed resource base, FF creates a new social problem. Potts $(2004,223)$ argues that in this way "environmental and social factors would have reinforced each other in influencing the cognitive evolution in great apes".

Hypotheses regarding the cognitive demands of ephemeral, dispersed food sources are of course a mainstay of research into primate cognitive evolution (e.g. Milton 1981; Parker and Gibson 1977), yet the recognition of the parallels between the ecological and social problems created by such a subsistence base constitutes a significant advance. It is necessarily the case that dispersed social relations are more demanding cognitively than their ecological analogue. All anthropoid primates are capable of tracking third-party relations, but that in FF social systems it is not just the absence of certain conspecifics that individuals need to keep track of; in addition, "animals need to recognize that the absence of a particular individual can affect the relative value of those that are present" (Barrett et al. 2003, 495). The need to adjust to a fluctuating social resource base and to negotiate a social world that is 
"partially virtual, rather than purely physically instantiated" (ibid.) suggest that FF sociality demands considerable object permanence skill.

\section{Mental time travel}

A further cognitive ability potentially related to the evolution and extension of FF social systems is that of Mental Time Travel (henceforth MTT), defined as the reconstruction or simulation of both past and future events using episodic memory or personal memories of the past, rather than the abstract facts that comprise semantic memory (Suddendorf and Corballis 1997). Suddendorf and Corballis $(1997,2007)$ suggest that the substrates underlying episodic memory are also employed when we mentally construct potential events in the future, as persistent errors in episodic memory recall suggest that the past, like the future, is 'constructed' rather than simply recalled (see the long psychological literature on mental models: Johnson-Laird 1983). Both episodic memory (Tulving 1983) and MTT (Suddendorf and Corballis 1997) were originally conceived of as purely human abilities, yet it seems that some animals demonstrate elements of 'episodic-like' memory and foresight. Clayton and colleagues (2003) have suggested that the caching behaviours of scrub jays imply both episodic-like memory (required for retrieval of cached items) and foresight, as jays that are aware of others observing their caching activities will only later re-cache the observed items if they themselves have stolen from the caches of others in the past (Clayton and Dickinson 1998; Emery and Clayton 2001). Among primates, recent studies suggest that chimpanzees, bonobos, and orang-utans are all capable of planning for future events via the understanding that tools may be useful in future situations (Mulcahy and Call 2006; Osvath and Osvath 2008), and Chimpanzees and orang-utans are also able to trade an immediate gain for a subsequent, larger gain (Osvath and Osvath 2008).

The need for MTT in FF social systems - particularly those of modern humans - relates to the ability to mentally model future encounters with individuals with whom interactions are not continual. . Like displacement, both episodic memory and MTT have been associated with linguistic capacities - a fact that has hampered their study in animals other than humans. Though Mulcahy and Call (2006) suggest that the precursor skills for MTT may have been present in the ancestor of all great apes, their studies were undertaken over relatively short periods of time. That apes such as bonobos can plan for activities that will take place up to 14 hours in the future may be perfectly in keeping with the scale of their own FF dynamics, but would not facilitate the kind of extensive spatio-temporal separation experienced routinely by modern humans. It is clear that, in expanding the scope of our social systems, humans have also placed extensive demands on the foresight elements of the MTT system. Barrett and colleagues $(2003,495)$ have even suggested that the core cognitive difference between humans and other apes might simply be "the number of alternative future scenarios that be can be managed and compared simultaneously".

\section{Inhibition and analogy}

A potential complexity of MTT involves the need to inhibit instinctive reactions while mentally simulating future eventsThe chimpanzees in Mulcahy and Call's (2006) experiments were able to inhibit the desire for an immediate, small gain in favour of securing large future gain, and study of inhibition in primates has recently suggested that this capacity might be better developed not in apes relative to monkeys but in in FF societies relative to non FF species ( Amici and colleagues 2008), . FF species were also significantly better than non-FF species at memory and withholding information tasks (Amici et al. 2009, 2010; see also Deaner et al. 2006), demonstratingnot only inhibition and limited foresight but also an understanding of other animals' motivations and probable reactions to learning of the existence of the food. These researchers suggest that "high levels of FF dynamics are 
associated with higher behavioural flexibility" (Amici et al. 2008, 1415), and argue that the large volumes of "fragmented and varying social information" (Amici et al. 2010, 194) stored by FF primates may have led to a fundamental re-organisation of the way in which that information is accessed.

The substantial quantities of information that must be managed by FF primates about third-party social relationships occurring out of view may thus have led to the evolution of analogical reasoning as a way of reducing cognitive demands (Barrett et al. 2003; Potts 2004; Aureli et al. 2008; Amici et al. 2010). Though analogical reasoning is often considered a hallmark of human cognition primates are able to extract general relations between sets of stimuli and sets of responses, and the learning of such general relations is likely to be more economical than the individual mapping of many stimulus-response pairs (Whiten 1996, Call 2001). This understanding of the relations between relations - equivalent to the use of analogy - is not only easily applicable in the social sphere (Call 2001), but may have first arisen there (Barrett et al. 2003; Aureli et al. 2008). Barrett and colleagues (2003) have suggested that one explicitly analogical form of reasoning that would have particularly benefitted animals in FF societies is the use of spatial descriptors to index temporal durationsThe understanding of time as continuum, so important in MTT, is predicated upon the understanding of space as a similar continuum (Boroditsky 2000), a mapping evident not only in the use of linguistic analogies such as references to 'lengths' of time, but in experiments in which no linguistic stimuli or responses are required (Casasanto and Boroditsky 2008). The gradual stretching of the social landscape in both space and time would have been an obvious stimulus to the development of social parallels to the physical time/space analogy. Indeed, Barrett and colleagues go as far as to suggest that theory of mind itself may have developed as "a specialized, socially-oriented form of analogical reasoning" based on the difficulties of managing dynamic social markets (Barrett et al. 2003, 496).

\section{The archaeology of fission-fusion}

The cognitive abilities highlighted above are more usually studied independently, yet it is immediately clear that similarities exist between them in terms of both observable behaviours and underlying processes. They are linked by the need for some ability to comprehend the flow of time, which some researchers have seen as the key to understanding the evolution of human cognition (e.g. Tulving 2002; Suddendorf et al. 2009). A search for archaeological evidence of an appreciation of the temporal in our ancestors will necessarily focus first on the question of whether activities leaving traces in the record reflect instances of foresight. Various such activities are discussed below, but the majority rely on lithics data, and while given the foregoing we can infer elements of foresight in the great ape clade as a whole, the archaeological record is essentially silent as to the pre-Oldowan development of these abilities in the earliest hominins prior to around $2.6 \mathrm{Ma}$.

From the very first appearance of Mode 1 technologies at sites such as Gona in Ethiopia (e.g. Semaw et al. 1997), archaeologists can begin to make inferences about levels of planning and foresight in hominin groups based on the complexity of the manufacture process and the extent to which raw materials and finished tools are transported around the landscape. Archaeological discussions of foresight as reflected in tool use frequentlyfocus on 'curation' (sensu Binford 1979, 1989), and tend to assume there is little in the way of forward planning evidenced in the 'expedient' technology of the Oldowan. However, Hallos (2005, 157) notes that there is no contradiction in the idea of 'planning to be expedient'; there are cognitive implications of the earliest tool behaviours that move beyond the immediate ability to produce a useful cutting edge, Binford's (1979) checklist for identifying archaeological examples of curation in fact involves numerous subtleties such as raw material selection and differential discard as well as the actual transport of materials, andgiven great apes' abilities, 
it is hardly surprising that there are clear instances of curation in even the earliest archaeological localities. Evidence of both raw material selectivity (e.g. Braun et al. 2009; Goldman-Neuman and Hovers 2009) and the transport of tools over distances implying an organization of space and time beyond that required for instant returns (e.g. Blumenschine et al. 2008) demonstrate that the behaviour of Oldowan hominins was more complex than suggested by the lithics alone.

The assumption that the transport of tools per se is a very basic form of planning for the future and, by extension, that tool transport distances will therefore at least loosely correlate with the spatio-temporal complexity of a society because movements between distant locales "require the scheduling of larger blocks of time to accomplish" (Brantingham 2006, 440). Similarly, Gamble $(1993,1996)$ has utilised the data of researchers such as Féblot-Agustins (1997) and Geneste (1988a, 1988b) to produce the first estimates of hominin home ranges from lithics datasets (Gamble and Steele 1999). This approach has proved particularly fruitful for the earlier Palaeolithic, when innovations in social organisation may have been equally if not more important than more visible innovations in technology (Coward and Grove 2011).

The increase in the distance over which tools were transported, from around ten $\mathrm{km}$ in the Oldowan to hundreds of kilometres in the Upper Palaeolithic, are the key archaeological elements Gamble uses to plot the emergence of the 'Social Landscape' (1993, 1996, 1998). However, it is clear that strategies of early lithic transport are just as important as the distances involved, . It is clear that FF groups must practise either periodic aggregation of the whole community (molecular) or regular, fluid exchange of individuals within subgroups (atomistic), or there can be no overarching community to which all individuals or subgroups belong, and from which they receive the benefits of community membership (Rodseth et al. 1991). From an archaeological perspective, the important difference between the atomistic and molecular systems is that they lead to alternative spatial patterns of aggregation and dispersal and thus different signatures in the record. The maintenance of bonds in all but very modern FF societies depends on face-to-face contact, with the duration and geographic scope of intervening separations determining the scale of the system. Without periodic aggregation or the exchange of individuals between subgroups, such bonds cannot be maintained at all, and this poses a very serious problem for the 'release from proximity' in FF societies.

The simple fact is that a chimpanzee-like (atomistic) FF system could not be expanded into the type of system practised by modern human hunter-gatherers, because it lacks a central 'socio-spatial' focus to guarantee re-aggregation. Whilst chimpanzees do occasionally re-use particular localities, these are almost always directly linked to subsistence practices (e.g. an ant hill, a termite mound, or a tree root used as an anvil). Further, chimpanzees feed as they go, and sleep in a location determined largely by the location of their last meal of the day; humans and, by inference, some hominins, transport food to locales at which they gather for the sake of aggregation. The highly circumscribed territories of chimpanzees thus ensure that the community maintains a degree of cohesion; without some kind of regularized aggregation locality an expanded chimpanzee-like community would simply fission permanently if stretched too far. We can conclude that existing chimpanzee communities endure at least partly because they have not undergone the release from proximity - they are both spatially and temporally limited in the scale of separations that occur between face-toface meetings.

The localities at which hominins regularly met first entered archaeological parlance as Isaac's (1978) 'home bases', influenced directly by studies of modern African huntergatherers (e.g. papers in Lee and DeVore 1968) and supposed parallels in the excavations of Olduvai (Leakey 1971; Potts 1988) and Koobi Fora (Isaac 1997). Severe criticism of the 
concept (e.g. Binford 1981) had the unfortunate result that the essential importance of a spatial focus to evolving hominin social systems has been under-appreciated ever since. The existence of central places (to use the modified terminology (Isaac 1983ff) is a pre-requisite for the release from proximity, yet these places need not have been imbued with profound social meaning from the start. Many animals employ central places, and those that also practice molecular FF are of particular interest.

Classic molecular FF primates such as hamadryas baboons are constrained to gather at central places by the lack of resources such as suitable sleeping cliffs and (seasonally) the scarcity of water sources (Swedell et al. 2008; Schreier and Swedell 2009; Schreier and Grove 2010). It seems highly likely that early hominin aggregations would have occurred in response either to limiting resources or to the presence of locations particularly abundant in favoured resources. With the addition of raw materials for tool-making to the list of basic subsistence resources, and the likelihood that the first manufacture of stone tools related to greater meat consumption, a number of localities, from lithic outcrops to waterholes to the locations of scavengeable carcasses, could have emerged as localities for initially temporary aggregations. Gradually, some of these localities may have taken on explicitly social meanings as loci of bond maintenance, not just areas rich in key resources. Once such nodes are established in the landscape, the paths between them also come to be shared by numerous interacting groups now operating within wider communities (e.g. Gamble 1996).

The structuring of the landscape can thus begin to emerge with limited cognitive capacities for the kind of time-dependent processing implied by problems such as displacement, object permanence, and mental time travel, yet it cannot be extended far beyond the basic primate template without development of these capacities. Most models of early hominin land use require some capacities for foresight that build on the basic idea of lithic transport as a reflection of planning for future action; many of these, in particular those of Binford (1984), Schick (1987), and Potts (1988), like Isaac (1978), are intended to explain the association of bones and stones in the early archaeological record, but each also shows how certain locations in the landscape come to be favoured over time due to the basic requirements of the foraging round. One of Binford's $(1981,1984)$ key criticisms of the home base model was that focal points, where they existed in the landscape, were determined largely by the local ecology rather than by social functions such as aggregation and foodsharing, and it is undoubtedly the most parsimonious explanation that aggregations prompted by distributions of resources, such as Binford's (1984) 'magnet places' (e.g. shade trees, lithic outcrops and water sources) would naturally attract accumulations of cultural material, and were only later exapted for explicitly social purposes asover time "hominins became less routed among places where nature had placed elements basic to life functions" (Binford 1984, 264), andlocalities repeatedly used by hominins were increasingly located to facilitate social exchange rather than to serve ecological necessity. This shift towards a more socially oriented use of the landscape would have required a greater level of planning and a more sophisticated spatio-temporal organisation as groups were able to fission for longer periods and to range over greater areas. Thus Binford's (1984) 'routed foraging' model can in fact be seen as evolutionarily antecedent to the development of Issac's home bases (1978). Similarly, the 'favoured places' of 'passive storage' resulting from persistent use of rich foraging areas as outlined by Schick (1987) can be seen as forerunners of the deliberate cache of stone suggested by Potts $(1983,1988)$ as an explanation for Oldowan localities at Olduvai Gorge whereby caches of tools and raw materials are spaced evenly in the landscape to reduce "the energy expended in bringing stone artifacts and animal bones together" (Potts 1988, 272). Potts $(1988,281 \mathrm{ff})$ explicitly addresses the extent of premeditation that would have been required for successful stone caching, noting that it necessitates as a minimum that hominins "had a range of information about their environment" and could "recall the distribution of 
resources" (Potts 1988, 281). Whilst such abilities are widespread throughout the animal world and do not require the kind of episodic memory often seen as instrumental to MTT, one could argue that the caching behaviour itself is indicative of at least the 'episodic-like' memory evidenced in modern corvids (e.g. Clayton et al. 2003). Furthermore, some archaeologists see the stone cache model as implying a mobility pattern towards the logistical end of the spectrum, a pattern demonstrated archaeologically only during the Upper Palaeolithic (e.g. Binford 1980, 1985; Straus 1986). It is clearly a behaviour that is quantitatively, if not qualitatively, different from the transport of tools by primates such as chimpanzees and capuchins, whose nut-cracking hammers are rarely transported more than a few hundred metres (e.g. Boesch and Boesch 1984; Ottoni and Izar 2008).

Nevertheless, the use of stone caches is still seen by most archaeologists as a pre-homebase phenomenon, and it is this later development that is key in facilitating Gamble's (1996) transition from the local hominin network to the social landscape and the development of broad-scale FF. Potts $(1988,287)$ noted that "the appearance of home bases involved changes in the spatial dimension of social life and feeding", but it is only through Gamble's (1996, 1998, 1999) network approach that the specific social benefits of this extended social milieu have become clear to archaeologists. The anchor provided by a home base is a pre-requisite for the release from proximity, but also provides a spatial focus for social exchange, whether of traditional commodities (hunted meat and gathered plant foods), or information.. A predetermined aggregation location allows fissioning subgroups to spread over a wider areathus establishing vital knowledge of an extensive territory. The importance of such information in prehistoric societies was noted by Gamble (1980) as key to the emergence of the social landscape. Studies of extant hunter-gatherers have demonstrated that individuals travel far further than is required to meet immediate subsistence needs, with longer trips often explained as being specifically for the purpose of maintaining social bonds (e.g. Gamble 1983, 1993; Kelly 1995; Whallon 2006). The equitable bonds created between groups in this way act as insurance mechanisms providing access to neighbouring territories during periods of resource stress (Gamble 1983; Kelly 1995), necessarily requiring a long-term, risk sensitive view of subsistence management and considerable planning for future contingencies.

Gamble $(1998,1999)$ argues that the social landscape may not have appeared until relatively late in human evolution, and the two thresholds he envisages accord well with archaeological evidence for the planning depth required to engage in extended fission-fusion sociality. An initial scaling-up is considered to coincide with the appearance of prepared-core technologies at around 300ka (Gamble 1998, 443). Not only does the Levallois mode of production itself demonstrate a degree of forward planning not seen in previous industries, but the distances raw materials are transported from this time onwards suggest a quantitative shift in the scale of landscape use (e.g. White and Pettitt 1995; Fernandes et al. 2008; Miller and Barton 2008) and imply an increase in temporal cognition of early Neanderthals over their late European $H$. Heidelbergensis ancestors. Prepared core technologies also become ubiquitous over a similar interval in the African MSA (e.g. Kuman 2001; McNabb 2001). Given the argument for independent evolution of prepared core techniques in the European Middle Palaeolithic (White and Ashton 2003), it is possible to suggest a geographically widespread threshold development at approximately $300 \mathrm{ka}$ that depended on a greater capacity for planning depth in tool manufacture. However, recent analyses by Grove and colleagues (2012, based on data compiled by Binford 2001) based on group size increases and latitudinal gradients in population density suggest that higher levels of group fission would only have occurred in populations of Neanderthals, H. sapiens and, perhaps, a few late H. heidelbergensis groups in northern latitudesA significant negative relationship between latitude and population density among hunter-gatherers, coupled with the finding of Dunbar (e.g. 1993; Aiello and Dunbar 
1993) that group size has increased in line with neocortex size throughout the last three million years, mean that hominin migrations towards higher latitudes have involved ever larger groups living at ever lower population densities. Since energetic constraints prevent the exploitation of vast territories by cohesive groups (see, e.g. Chapman et al. 1995), groups are obliged to fission for foraging purposes. Thus we can argue that the social dynamics inferred for hominin populations from $\sim 300 \mathrm{ka}$ onwards demonstrate the need for advanced temporal cognition to facilitate ever-increasing periods of separation between individual subgroups.

A feature of the kind of multilevel societies in place by this time is that they lead to nested hierarchies composed of ever-larger tiers of social grouping (Dunbar 2003; Zhou et al. 2005; Grove 2010b, 2010c). Zhou et al. (2005), show recurrent groupings at approximately 5, 15, 50, and 150 individuals in both modern hunter-gatherer and sedentary western populations. Larger, periodic groupings occur at group sizes of approximately 500 and 1500 individuals (see also Hill and Dunbar 2003; Hamilton et al. 2007). Grove (2010b, 2011) has shown that later prehistoric monument distributions are consistent with this grouping pattern. However, it remains unclear exactly when in prehistory the 'outer' layers of 500 and 1500 were established. Whilst analyses of neocortex ratios in extant primates suggest a cognitive group size of approximately 150 for modern humans (Dunbar 1993; Aiello and Dunbar 1993), it is clear that something beyond encephalisation was required to establish the regional relations that typify modern hunter-gatherers (Grove and Coward 2008; Gamble 2010; Coward and Grove 2011). Gamble (1998) and Dunbar (2009) have suggested that the 300ka threshold would have been accompanied by at least a rudimentary form of language, which may have made possible the 500-strong 'megaband' as a standard element of hominin regional interaction.

The second threshold postulated by Gamble - the appearance of the social landscape itself - is dated to between 100 and $60 \mathrm{ka}$, and coincides with the establishment of the full, 1500-strong ethnolinguistic tribe and, by inference, the development of modern-like syntactical language. The fundamental shift here involves the "stretching of social life beyond the practical limits set on co-presence interaction by time, the body and space" (Gamble 1998, 440) into extended networks which are dependent upon the ability to view artefacts as symbols of "distant persons who in absentia now determine the performance of social relationships" (Gamble 1999, 95). The equation of symbolic artefacts with extended networks, and the corollary that Palaeolithic societies lacking such networks would have been unable - or perhaps were never required - to produce such artefacts, hints at profound social developments during the latter stages of the MSA and in the Upper Palaeolithic of Europe. The notion that spatio-temporal 'distanciation' depends on the production of symbolic artefacts again implies that the flow of information is of paramount importance (Gamble 1980), and suggests that language, which is considered to have emerged during or before the $300 \mathrm{ka}$ threshold, would have become a fully modern-like system of communication during the emergence of the social landscape. Modern externalists such as Clark and Chalmers (1998, 18) have argued that the appearance of behavioural modernity may have been scaffolded by a "linguistically-enabled extension of cognition", yet the displacement that language implies is perhaps extended even further in both time and space by the use of artefacts, which can play precisely the role Clark and Chalmers envisage for language by allowing ideas to "migrate between minds" (Mithen 2000, 214); given the distances artefacts were transported by the Late MSA and Upper Palaeolithic periods, such ideas could have migrated rapidly, and at continental scales.

Two examples of artefacts give an impression of the social landscape as established during the Upper Palaeolithic. The first is Vanhaeren and d'Errico's (2006) attempt to map the cultural geography of Aurignacian Europe using seriation and correspondence analyses of personal ornament types. These authors identify fifteen geographically distinct personal 
ornament 'sets' allied to geographical areas ranging from Greece in the south-east to Belgium in the north-west, arguing that they represent ethnolinguistic groupings akin to the tribes of modern hunter-gatherers. This finding appears to suggest a symbolism of exclusion among the first $H$. sapiens settlers of Europe, with personal ornaments reflecting regional identity and, by inference, establishing membership of an in-group to the exclusion of neighbouring tribes. Group signalling is certainly a common theme in studies of modern symbolic communication, yet Gamble's $(1993,1998)$ approach suggests that exclusion would have been a feature of local groupings prior to the emergence of the social landscape and that, after this threshold, the release from proximity created an unbounded social sphere in which relations were built on the possibilities of inclusion.

The second example of widespread social and symbolic interaction comes from Gamble's (1982) work on the Gravettian 'Venus figurines', and shows how a single artefact form can in fact unite, rather than create boundaries between populations over vast areas. Gamble $(1982,99)$ argues that the appearance of a class of items such as the Venus figurines was "a reflection of changing circumstances that required new means by which information could be transmitted and received". The sheer scale of Venus figurine distribution - with very similar examples being found across almost the whole area surveyed by Vanhaeren and d'Errico (2006) for regional differences - suggests to Gamble (1982) that a limited set of stylistic rules governed figurine production, allowing socially distant groups to communicate with each other. The 'changing circumstances' could thus relate to an expansion in the scale of social interaction, with the negotiation of equitable relationships with distant groups providing advantages in terms of risk mitigation (Gamble 1993; Whallon 2006) and the need for a symbolic common currency. Social risk mitigation over large scales might have been of particular value during the increasingly harsh conditions of the Gravettian, whereas the relative climatic affluence of the Aurignacian could have encouraged the formation of neighbouring, but self-sufficient and perhaps competing populations. Alternatively, the two approaches could reflect contemporaneous phenomena. Gamble (1982) suggests that the use of common symbolic artefacts could cross-cut precisely the kinds of linguistic differences inferred by Vanhaeren and d'Errico (2006); whereas language is tribal, a common, simple symbolic currency such as the use of figurines could act as a truly extensive director of social intercourse.

\section{Conclusions}

The network approach to Palaeolithic society established by Gamble (1993, 1996, 1998, 1999) postulates a transformation of hominin society from a primate-like system, in which bonds are maintained through continual co-presence, into a distinctly human system in which relationships are maintained even in the absence of spatial proximity. This stretching of the human social system, involving the fission of subgroups for extended periods of time and the maintenance of equitable bonds with groups in distant geographical areas, brings a number of cognitive challenges. The social brain hypothesis has focused primarily on group size as an index of social complexity, yet in recent years this has been expanded to accommodate more fine-grained aspects of human social evolution such as the development of an ape-like fission-fusion pattern into the global web of networks visible among humans today. A combination of Gamble's network approach and the perspective on fission-fusion emerging from research into the social brain highlights a number of key cognitive attributes that would have facilitated the 'release from proximity' that is the hallmark of modern society. Looking into the archaeological record, clear signs of these cognitive attributes can be mapped chronologically as we trace the development of hominin societies towards modernity.

As Gamble has stressed time and again, the stones and bones of the Palaeolithic need not be silent on the subject of society. Beginning with the earliest evidence of raw materials 
and tools being transported around ancient environments, there is evidence for the kinds of cognitive abilities that would have accompanied the expansion of humans out of Africa and beyond. Displacement, object permanence, and mental time travel overlap in requiring the ability to hold objects (or agents) in mind when they are not physically present - a skill that would have developed in concert with the expanding spatio-temporal scope of hominin societies. From these initial skills more elaborate, humanlike abilities emerge, such as the capacity for analogical thought; the latter is seen particularly through the non-linguistic mappings of spatial extension onto temporal duration. As a potential demonstration of such analogical abilities, the appearance of symbolic artefacts is of particular importance to archaeologists. While evidence of trade and exchange are certainly valuable in establishing the scale of early hominin societies, it is at the point where artefacts begin to stand for distant places or people that a fully modern cognition emerges.

Gamble $(1998,440)$ has argued that "when artefacts become people, we have achieved that release from proximity which is our primate social heritage", yet this very social use of analogy is mediated by more than simply a spatio-temporal stretching of society. As is clear from the comparison of Aurignacian beads and Gravettian Venus figurines above, overlapping boundaries at multiple scales are established at various places in the landscape. These boundaries are traversed as groups disperse and aggregate, transforming the meanings of the artefacts they carry; it is this expanded fission-fusion process that requires "the transformation in value from local to distant, from object to symbol" (Gamble 1999, 95). Thus material culture plays a far greater role in the evolution of hominin society than many archaeologists would acknowledge, not least as the medium of communication for the truly long-distance social exchange necessitated by expanded fission-fusion social systems. It is only when fission-fusion society reaches this uniquely human level of extension that "the development of society through the elaboration of material culture is set in process" (Gamble 1982, 99).

\section{References}

Aiello, L. C. and R. I. M. Dunbar. 1993. Neocortex size, group size, and the evolution of language. Current Anthropology 34, 184-193.

Altmann, S. A. 1967. The structure of primate social communication, in S. A. Altmann (ed.) Social Communication among Primates. Chicago: University of Chicago Press, pp325-362.

Amici, F., F. Aureli and J. Call. 2008. Fission-fusion dynamics, behavioral flexibility, and inhibitory control in primates. Current Biology 18, 1415-1419.

Amici, F., J. Call and F. Aureli. 2009. Variation in withholding of information in three monkey species. Proceedings of the Royal Society B-Biological Sciences 276, 3311-3318.

Amici, F., F. Aureli and J. Call. 2010. Monkeys and Apes: Are Their Cognitive Skills Really So Different? American Journal of Physical Anthropology 143, 188-197.

Aureli, F., C. M. Schaffner, C. Boesch, S. K. Bearder, J. Call, C. A. Chapman, R. Connor, A. Di Fiore, R. I. M. Dunbar, S. P. Henzi, K. Holekamp, A. H. Korstjens, R. Layton, P. Lee, J. Lehmann, J. H. Manson, G. Ramos-Fernandez, K. B. Strier, and C. P. Van Schaik. 2008. Fission-Fusion Dynamics New Research Frameworks. Current Anthropology 49, 627-654.

Barrett, L., P. Henzi and R. Dunbar. 2003. Primate cognition: from 'what now?' to 'what if?'. Trends in Cognitive Sciences 7, 494-497.

Binford, L. R. 1978. Dimensional analysis of behavior and site structure: learning from an Eskimo hunting stand. American Antiquity 43, 330-361.

Binford, L. R. 1979. Organisation and formation processes: looking at curated technologies. Journal of Anthropological Research 35, 255-273.

Binford, L. R. 1980. Willow smoke and dogs' tails: hunter-gatherer settlement systems and archaeological site formation. American Antiquity 45, 4-20. 
Binford, L. R. 1981. Bones: Ancient Men and Modern Myths. New York: Academic Press. Binford, L. R. 1984. Faunal Remains from Klasies River Mouth. New York: Academic Press. Binford, L. R. 1985. Human ancestors: Changing views of their behavior. Journal of Anthropological Archaeology 4, 292-327.

Binford, L. R. 1989. Isolating the transition to cultural adaptations: an organisational approach, in E. Trinkaus (ed.) The Emergence of Modern Humans. Cambridge: Cambridge University Press, pp18-41.

Binford, L. R. 2001. Constructing frames of reference: an analytical method for archaeological theory building using ethnographic and environmental data sets. Berkeley, CA: University of California Press.

Birdsell, J. B. 1958. On population structure in generalized hunting and collecting populations. Evolution 12, 189-205.

Birdsell, J. B. 1968. "Some predictions for the Pleistocene based on equilibrium systems among recent hunter-gatherers, in R. Lee and I. DeVore (eds.) Man the Hunter. Chicago: Aldine, pp229-240.

Blumenschine, R. J., F. T. Masao, J. C. Tactikos, and J. I. Ebert. 2008. Effects of distance from stone source on landscape-scale variation in Oldowan artifact assemblages in the PaleoOlduvai Basin, Tanzania. Journal of Archaeological Science 35, 76-86.

Boesch, C., and H. Boesch. 1984. Mental map in wild chimpanzees (Pan troglodytes verus): An analysis of hammer transports for nut cracking. Primates 25, 160-170.

Boroditsky, L. 2000. Metaphoric structuring: understanding time through spatial metaphors. Cognition 75, 1-28.

Brantingham, P. J. 2006. Measuring forager mobility. Current Anthropology 47, 435-459.

Braun, D. R., T. Plummer, J. V. Ferraro, P. Ditchfield, and L. C. Bishop. 2009. Raw material quality and Oldowan hominin toolstone preferences: evidence from Kanjera South, Kenya. Journal of Archaeological Science 36, 1605-1614.

Call, J. 2001. Chimpanzee social cognition. Trends in Cognitive Sciences 5, 388-393.

Casasanto, D. and L. Boroditsky. 2008. Time in the mind: Using space to think about time. Cognition 106, 579-593.

Chapman, C. A., R. W. Wrangham, and L. J. Chapman. 1995. Ecological constraints on group size: An analysis of spider monkey and chimpanzee subgroups. Behavioral Ecology and Sociobiology 36, 59-70.

Cheney, D. L. and R. M. Seyfarth. 1990. How Monkeys See the World. Chicago: University of Chicago Press.

Clark, A. and D. Chalmers. 1998. The extended mind (Active externalism). Analysis 58, 719.

Clayton, N. S. and A. Dickinson. 1998. Episodic-like memory during cache recovery by scrub jays. Nature 395, 272-274.

Clayton, N. S., T. J. Bussey, and A. Dickinson. 2003. Can animals recall the past and plan for the future? Nature Reviews Neuroscience 4, 685-691.

Coward, F. and M. Grove. 2011. Beyond the tools: social innovation and hominin evolution. PaleoAnthropology 2011, 111-129.

Deaner, R. O., C. P. van Schaik and V. Johnson. 2006. Do some taxa have better domaingeneral cognition than others? A meta-analysis of nonhuman primate studies. Evolutionary Psychology 4, 149-196.

Dunbar, R. I. M. 1993. Coevolution of neocortical size, group size and language in humans. Behavioral and Brain Sciences 16, 681-694.

Dunbar, R. I. M. 1998. The social brain hypothesis. Evolutionary Anthropology 6:178-190. 
Dunbar, R. I. M. 2003. The social brain: Mind, language, and society in evolutionary perspective. Annual Review of Anthropology 32, 163-181.

Dunbar, R. I. M. 2009. Why only humans have language, in C. Knight and R. Botha (eds.) The Prehistory of Language. Oxford: Oxford University Press, pp12-35.

Emery, N. J. and N. S. Clayton. 2001. Effects of experience and social context on prospective caching strategies by scrub jays. Nature 414, 443-446.

Feblot-Augustins, J. 1997. La Circulation des matieres premieres au Paleolithique. Liege: ERAUL 75.

Fernandes, P., J.-P. Raynal and M.-H. Moncel. 2008. Middle Palaeolithic raw material gathering territories and human mobility in the southern Massif Central, France: First results from a petro-archaeo logical study on flint. Journal of Archaeological Science 35, 23572370 .

Gamble, C. 1980. Information exchange in the Palaeolithic. Nature 283, 522-523.

Gamble, C. 1982. Interaction and alliance in Palaeolithic society. Man 17, 92-107.

Gamble, C. 1983. Culture and society in the Upper Palaeolithic of Europe, in G. N. Bailey (eds.) Hunter-Gatherer Economy in Prehistory.Cambridge: Cambridge University Press, pp201-211.

Gamble, C. 1993. Exchange, foraging, and local hominid networks, in C. Scarre and F. Healy (eds.) Trade and Exchange in Prehistoric Europe. Oxford: Oxbow Books, pp35-44.

Gamble, C. 1996. Making tracks: Hominid networks and the evolution of the social landscape, in J. Steele and S. Shennan (eds.) The Archaeology of Human Ancestry: Power, Sex, and Tradition. London: Routledge, pp253-277.

Gamble, C. 1998. Palaeolithic society and the release from proximity: a network approach to intimate relations (Human social evolution). World Archaeology 29, 426-449.

Gamble, C. 1999. The Palaeolithic Societies of Europe. Cambridge: Cambridge University Press.

Gamble, C. 2007. Origins and Revolutions. Cambridge: Cambridge University Press.

Gamble, C. 2010. Technologies of separation and the evolution of social extension, in R. I. M. Dunbar, C. Gamble and J. Gowlett (eds.) Social Brain, Distributed Mind. Oxford: Oxford University Press, pp17-42.

Gamble, C. and J. Steele. 1999. Hominid ranging patterns and dietary strategies, in H. Ulrich (ed.) Hominid Evolution: Lifestyles and Survival Strategies. Gelsenkirchen: Editions Archaea, pp396-409.

Geneste, J. 1988a. Systemes d'approvisionnement en matieres premieres au Paleolithique moyen et au Paleolithique superieur en Aquitaine, in J. K. Kozlowski (ed.) L'Homme de Neandertal, vol.8: La Mutation. Liege: ERAUL 35, pp61-70.

Geneste, J. 1998b. Les industries de la Grotte Vaufrey: technologie du debitage, economie et ciculation de la matiere premiere lithique, in J.-P. Rigaud (ed.) La Grotte Vaufrey a Cenac et Saint-Julien (Dordogne): Paleoenvironments, Chronologie et Activites Humaines. Paris: Memoires de la Societe Prehistorique Francaise 19, pp441-518.

Goldman-Neuman, T. and E. Hovers. 2009. Methodological considerations in the study of Oldowan raw material selectivity: Insights from A.L. 894 (Hadar, Ethiopia), in E. Hovers and D. R. Braun (eds.) Interdisciplinary Approaches to the Oldowan. Dordrecht: Springer, pp7184.

Gomez, J. C. 2005. Species comparative studies and cognitive development. Trends in Cognitive Sciences 9, 118-125.

Grove, M. 2009. Hunter-gatherer movement patterns: Causes and constraints. Journal of Anthropological Archaeology 28, 222-233.

Grove, M. 2010a. Logistical mobility reduces subsistence risk in hunting economies. Journal of Archaeological Science 37, 1913-1921. 
Grove, M. 2010b. Stone circles and the structure of Bronze Age society. Journal of Archaeological Science 37, 2612-2621.

Grove, M. 2010c. "The archaeology of group size, in R. Dunbar, C. Gamble and J. Gowlett (eds.) Social Brain, Distributed Mind. Oxford: Oxford University Press, pp39`-411.

Grove, M. 2011. An archaeological signature of multi-level social systems: The case of the Irish Bronze Age. Journal of Anthropological Archaeology 30, 44-61.

Grove, M. and F. Coward. 2008. From individual neurons to social brains. Cambridge Archaeological Journal 18, 387-400.

Grove, M., E. Pearce and R. I. M. Dunbar. 2012. Fission-fusion and the evolution of hominin social systems. Journal of Human Evolution 62, 191-200.

Hallos, J. 2005. "15 minutes of fame": Exploring the temporal dimension of Middle Pleistocene lithic technology. Journal of Human Evolution 49, 155-179.

Hamilton, M. J., B. T. Milne, R. S. Walker, O. Burger and J. H. Brown. 2007. The complex structure of hunter-gatherer social networks. Proceedings of the Royal Society, London, 274B, 2195-2202.

Hill, R. A. and R. I. M. Dunbar. 2003. Social network size in humans. Human Nature-an Interdisciplinary Biosocial Perspective 14, 53-72.

Hockett, C. F. 1960. Logical considerations in the study of animal communication, in W. E. Lanyon and W. N. Tavolga (eds.) Animal Sounds and Communication. Washington, D.C.: American Institute of Biological Sciences, pp392-430.

Hockett, C. F. 1963. The problem of universals in language, in J. H. Greenberg (ed.) Universals of Language. Cambridge, MA: M.I.T. Press, pp1-22.

Hockett, C. F. and S. A. Altmann. 1968. A note on design features, in T. A. Sebeok (ed.) Animal Communication. Bloomington: Indiana University Press, pp61-72.

Isaac, G. L. 1978. The food-sharing behaviour of proto-human hominids. Scientific American 238, 90-108.

Isaac, G. L. 1983. Bones in contention: competing explanations for the juxtaposition of Early Pleistocene artefacts and faunal remains, in Animals and Archaeology: Hunters and Their Prey. Oxford: British Archaeology Reports, pp3-19.

Isaac, G. L. 1997. Koobi Fora Research Project, Volume 5: Plio-Pleistocene Archaeology. Oxford: Clarendon Press.

Johnson-Laird, P. 1983. Mental Models. Cambridge: Cambridge University Press.

Kappeler, P. M. and C. P. van Schaik. 2002. Evolution of primate social systems. International Journal of Primatology 23, 707-740.

Kelly, R. L. 1995. The Foraging Spectrum: Diversity in Hunter-Gatherer Lifeways. Washington, DC: Smithsonian Institution Press.

Kuman, K. 2001. An Acheulean factory site with prepared core technology near Taung, South Africa. South African Archaeological Bulletin 56, 8-22.

Kummer, H. 1971. Primate Societies: Group Techniques of Ecological Adaptation. Chicago: Aldine.

Leakey, M. D. 1971. Olduvai Gorge, Volume 3: Excavations in Beds I and II, 1960-1963. Cambridge: Cambridge University Press.

Lee, R. 1968. What hunters do for a living, or how to make out on scarce resources, in R. Lee and I. DeVore (eds.) Man the Hunter. Chicago: Aldine, pp30-48.

Lee, R. and I. DeVore (eds.) 1968. Man the Hunter. Chicago: Aldine.

Lehmann, J., Lee, P. C. and Dunbar, R. I. M. In Press. Unravelling the evolutionary function of communities, in R. I. M. Dunbar, C. Gamble and J. A. J. Gowlett (eds.) The Lucy Project: The Benchmark Papers. Oxford: Oxford University Press.

Lieberman, D. E. and J. J. Shea. 1994. Behavioral differences between archaic and modern humans in the Levantine Mousterian. American Anthropologist 96, 300-332. 
Lieberman, P. 1984. The Biology and Evolution of Language. Cambridge, MA: Harvard University Press.

McNabb, J. 2001. The shape of things to come: A speculative essay on the role of the Victoria West phenomenon at Canteen Koppie, during the South African Earlier Stone Age, in S. Milliken and J. Cook (eds.) A Very Remote Period Indeed: Papers on the Palaeolithic Presented to Derek Roe. Oxford: Oxbow Books, pp37-46.

Miller, A. and C. M. Barton. 2008. Exploring the land: a comparison of land-use patterns in the Middle and Upper Palaeolithic of the western Mediterranean. Journal of Archaeological Science 35, 1427-1437.

Milton, K. 1981. Diversity of plant foods in tropical forests as a stimulus to mental development in primates. American Anthropologist 83, 534-548.

Mithen, S. J. 2000. Mind, brain, and material culture: An archaeological perspective, in P. Carruthers and A. Chamberlain (eds.) Evolution and the Human Mind. Cambridge: Cambridge University Press, pp207-217.

Mulcahy, N. J. and J. Call. 2006. Apes save tools for future use. Science 312, 1038-1040.

Murdock, G. P. 1949. Social Structure. New York: MacMillan.

Murdock, G. P. 1969. Ethnographic Atlas. Pittsburgh: University of Pittsburgh Press.

Osvath, M. and H. Osvath. 2008. Chimpanzee (Pan troglodytes) and orangutan (Pongo abelii) forethought: self-control and pre-experience in the face of future tool use. Animal Cognition 11, 661-674.

Ottoni, E. B. and P. Izar. 2008. Capuchin monkey tool use: Overview and implications. Evolutionary Anthropology 17, 171-178.

Parker, S. T. and K. R. Gibson. 1977. Object manipulation, tool use and sensorimotor intelligence as feeding adaptations in cebus monkeys and great apes. Journal of Human Evolution 6, 623-641.

Perreault, C. and P. J. Brantingham. 2011. Mobility-driven cultural transmission along the forager-collector continuum. Journal of Anthropological Archaeology 30, 62-68.

Piaget, J. 1952. The Origins of Intelligence in Children. New York: International University Press.

Potts, R. 1983. Foraging for faunal resoutrces by Early Hominids at Olduvai Gorge, Tanzania, in J. CLutton-Brock and C. Grigson (eds.) Animals and Archaeology 1: Hunters and their prey. Oxford: BAR International Series 163, pp51-62.

Potts, R. 1988. Early Hominid Activities at Olduvai. New York: Aldine de Gruyter.

Potts, R. 2004. Paleoenvironmental basis of cognitive evolution in great apes. American Journal of Primatology 62, 209-228.

Roberts, S. G. B. 2010. Constraints on social networks, in R. I. M. Dunbar, C. Gamble and J. Gowlett (eds.) Social Brain, Distributed Mind. Oxford: Oxford University Press, pp115-134.

Rodseth, L., R. W. Wrangham, A. M. Harrigan and B. B. Smuts. 1991. The human community as a primate society. Current Anthropology 32, 221-254.

Schick, K. D. 1987. Modeling the formation of Early Stone Age artifact concentrations. Journal of Human Evolution 16, 789-807.

Schreier, A. L. and M. Grove. 2010. Ranging patterns of hamadryas baboons: random walk analyses. Animal Behaviour 80, 75-87.

Schreier, A. L. and L. Swedell. 2009. The Fourth Level of Social Structure in a Multi-Level Society: Ecological and Social Functions of Clans in Hamadryas Baboons. American Journal of Primatology 71, 948-955.

Semaw, S., P. Renne, J. W. K. Harris, C. S. Feibel, R. L. Bernor, N. Fesseha and K. Mowbray. 1997. 2.5-million-year-old stone tools from Gona, Ethiopia. Nature 385, 333-336.

Sigg, H. and Stolba, A. 1981. Home range and daily march in a hamadryas baboon troop. Folia Primatologica 36, 40-75. 
Straus, L. G. 1986. Late Wurm adaptive systems in Cantabrian Spain: The case of Eastern Asturias. Journal of Anthropological Archaeology 5, 330-368.

Suddendorf, T., D. R. Addis and M. C. Corballis. 2009. Mental time travel and the shaping of the human mind. Philosophical Transactions of the Royal Society B-Biological Sciences 364, 1317-1324.

Suddendorf, T. and M. C. Corballis. 1997. Mental time travel and the evolution of the human mind. Genetic Social and General Psychology Monographs 123, 33-167.

Suddendorf, T. and M. C. Corballis. 2007. Mental time travel across the disciplines: The future looks bright. Behavioral and Brain Sciences 30, 335-351.

Swedell, L., G. Hailemeskel and A. Schreier. 2008. Composition and seasonality of diet in ild hamadryas baboons: Preliminary findings from Filoha. Folia Primatologica 79, 476-490.

Thompson, M. E., Kahlenberg, S. M., Gilby, I. C. and Wrangham, R. W. 2007. Core area quality is associated with variance in reproductive success among female chimpanzees at Kibale National Park. Animal Behaviour 73, 501-512.

Tulving, E. 1983. Elements of Episodic Memory. Oxford: Clarendon Press.

Tulving, E. 2002. Episodic memory: From mind to brain. Annual Review of Psychology 53, $1-25$.

Vanhaeren, M. and F. d'Errico. 2006. Aurignacian ethno-linguistic geography of Europe revealed by personal ornaments. Journal of Archaeological Science 33, 1105-1128.

Washburn S. 1982. Fifty years of studies on human evolution. Bulletin of the American Academy of Arts and Sciences 35:25-39.

Whallon, R. 2006. Social networks and information: Non-"utilitarian" mobility among hunter-gatherers. Journal of Anthropological Archaeology 25, 259-270.

White, M. and N. Ashton. 2003. Lower Palaeolithic core technology and the origins of the Levallois method in northwestern Europe. Current Anthropology 44, 598-609.

White, M. J. and P. P. Pettitt. 1995. Technology of early Palaeolithic western Europe: innovation, variability and a unified framework. Lithics 16, 27-40.

Whiten, A. 1996. Imitation, pretense, and mindreading: Secondary representation in comparative primatology and developmental psychology? Reaching into thought: The minds of the great apes.

Yellen, J. 1977. Archaeological Approaches to the Present: Models for Reconstructing the Past. New York: Academic Press.

Zhou, W. X., D. Sornette, R. A. Hill and R. I. M. Dunbar. 2005. Discrete hierarchical organization of social group sizes. Proceedings of the Royal Society B-Biological Sciences 272, 439-444. 